\title{
Kant e o Idealismo Alemão
}

Flamarion Tavares Leite*

\author{
DOI 10.20399/P1982-999X.2016v1n2pp16-27
}

\begin{abstract}
Resumo
O presente estudo toma como fulcro a resposta de Kant ao empirismo cético e ao determinismo de Hume, encontrada na obra que inaugura o período crítico - a Crítica da razão pura -, bem como na Crítica da razão prática, cujo objeto é a análise da liberdade. Examina e expõe a evolução da filosofia kantiana, que culmina no criticismo e seu consectário - o idealismo transcendental -, para postular que o surgimento do idealismo alemão se deu a partir da Crítica da razão pura. Este idealismo perpassa por Fichte e Schelling, encontrando seu desfecho em Hegel. Para atingir seu desiderato, este trabalho tem início com a vida e escritos do filósofo de Königsberg, adentra a gênese do idealismo, onde expõe o criticismo kantiano, como corrente filosófica que veio a superar o racionalismo dogmático e o empirismo cético, mostrando como se coloca o problema gnosiológico para Kant, a partir de sua revolução copernicana. Nessa traça, sublinha que, no afã de produzir conhecimento, a razão pura teórica se perde em paralogismos e antinomias. A terceira antinomia trata da oposição entre liberdade e necessidade da natureza, cuja solução abre o espaço de possibilidade para a reflexão prática. O exame da liberdade será objeto da Crítica da razão prática, através da realidade da obrigação moral.
\end{abstract}

Palavras-chave: Hume; Kant; Fichte; Schelling; Hegel; Empirismo; Idealismo.

\begin{abstract}
This work - study - has, as its support, Kant's answer to Hume's ceptical empirism and determinism, found out in the work that opens out the critical period - The Critique of pure reason - and work that opens - as well as in The Critique of practical reason, being its - concerning the "pratical reason ' subject/object - is the analysis regarding to liberty/freedom. It - this study - examines and deals with the Kantian philosophy, which reaches its top in the so called criticism and its 'consectarium', i.e. resulting mind process - the transcendental Idealism - in order to postulate that the German Idealism spring off has occurred departing from the 'The Critique of pure reason'. This idealism trends throughout Fichte and Schelling reaching its rightest point in Hegel. In order to arrive at - reach - its 'desideratum' - its highest purpose - this work - begins, from the Könnigsberg Philosopher's life and writings, penetrates the Idealism genesis which deals with in the Kantian Criticism as a philosophical current that has come to that has arrived to the point of - overcome the dogmatic rationalism and the skeptical empirism, showing out the way how is Kant points out the gnosiological problem, departing from its Copernican revolution. In this trial, it underlines that, in the eagerness of producing - acknowledgement, the theoretic pure reason uses to lose itself in - thought paralogisms and antinomies. The third antinomy deals with the opposition between-regarding to liberty-freedom and nature need which the solution opens out of the possibility space-ground concerning the practical reflection. The exam-test-regarding to liberty will be the subject or object - of the Critique concerning the pratical reason through the moral obligation reality.
\end{abstract}

Key-words: Hume; Kant; Fichte; Schelling; Hegel; Empirism; Idealism.

\section{Introdução}

Immanuel Kant, conhecido como o filósofo das três Críticas - Crítica da razão pura, Crítica da razão prática e Crítica do juízo -, nasceu no dia 22 de abril de 1724,

\footnotetext{
* Doutor em Direito pela PUC-SP. Professor da UFPB (aposentado), do UNIPÊ e da FESP. Mestre em Filosofia. Especialista em Integração Econômica e Direito Internacional Fiscal pela Universidade Técnica de Lisboa/UnB/ESAF, com estágio na União Europeia (Bruxelas) e Ministério das Finanças de Portugal (Lisboa). Professor Convidado (Assistente) da União Europeia no Curso de Especialização em Integração Econômica e Direito Internacional Fiscal da Escola de Administração Fazendária - ESAF, Brasília-DF. Autor dos livros Manual de Filosofia Geral e Jurídica: das origens a Kant, Malheiros, 2013 (4ª edição); 10 Lições sobre Kant, Vozes, 2015 ( $9^{\mathrm{a}}$ edição); Os nervos do Poder: uma visão cibernética do Direito, Max Limonad, 2001; O conceito de Direito em Kant, Ícone, 1996. Coordenador da Coleção 10 lições da Editora Vozes, de Petrópolis-RJ. Presidente da Academia Paraibana de Letras Maçônicas. Membro Efetivo da Academia Paraibana de Letras Jurídicas.
} 
em Königsberg (Prússia oriental), na rua dos seleiros, onde seu pai exercia esse ofício. Filho de Johann Georg Kant, homem laborioso, honesto, que tinha horror à mentira, e de Anna Regina Reuter, mulher profundamente religiosa, que lhe ministrou sólida educação moral e, antes de morrer, o internou no Collegium Fridericianum, dirigido por Francisco Alberto Schultz, fervoroso adepto do pietismo ${ }^{1}$ Kant afirmava que seus antepassados provinham da Escócia e que seu pai escrevia o sobrenome com $\mathrm{C}$ (Cant), razão por que o filósofo decidiu adotar o $\mathrm{K}$ inicial, evitando que se pronunciasse Tsant ${ }^{2}$.

Kant permaneceu no Fridericianum pelo espaço de nove anos, de 1732 a 1740, ano em que ingressou na Universidade, onde foi profundamente influenciado por Martin Knutzen, conhecido por seus bem acolhidos escritos, pietista como Schultz e discípulo de Wolff, cujo método é um racionalismo sistemático, que se esforça por julgar tudo à mão de princípios - e não de sentimentos - e por deduzir logicamente cada proposição. Tal será a atitude de $\mathrm{Kant}^{3}$ Não por outro motivo, quando penetramos no frio castelo de mármore do pensamento kantiano, percebemos a argumentação estrita e o proceder científico de Wolff, o maior dos dogmáticos, ${ }^{4}$ nas palavras do metódico e pouco romântico professor Kant.

A Knutzen deveu Kant o conhecimento das obras de Newton, que constituíram a prova experimental da possibilidade de uma ciência a priori da natureza. É nesse período que Kant publica sua primeira obra - Pensamentos sobre a verdadeira avaliação das forças vivas (1747) -, em que procura conciliar as ideias de Descartes com as de Leibniz no tocante à medida da força de um corpo em movimento.

Após a morte do pai (1747), Kant, para ganhar a vida, torna-se preceptor, função que exerceu durante nove anos. Todavia, prossegue com seus estudos e, em 1755, publica História universal da natureza e teoria do céu, na qual trata do sistema e da origem mecânica do universo segundo os princípios de Newton, preludiando a teoria sobre a formação dos astros, que Laplace iria apresentar quarenta anos depois.

Em 1755, tendo obtido da Universidade a "promoção" - espécie de diploma de conclusão de curso -, graças a uma dissertação sobre o fogo, e a "habilitação" - que lhe dá direito a abrir um curso livre -, por uma dissertação sobre os primeiros princípios do conhecimento metafísico, Kant torna-se Docente Livre (Privatdozent), ou seja, dá cursos livres, financiados diretamente pelos próprios estudantes, ensinando matemática, lógica, moral, física, pirotecnia, teoria das fortificações, enciclopédia filosófica, teologia natural, antropologia, a doutrina do belo e do sublime.

No decurso desses anos (1755-1770) Kant lê Rousseau, de quem sofre profunda influência, sobretudo nas questões morais, tendo aprendido a não depreciar as inclinações naturais do homem. A ciência física a priori como fato, eis o que tinha encontrado em Newton; a moralidade como fato, eis o que Rousseau lhe fez ver ${ }^{5}$.

\footnotetext{
${ }^{1} \mathrm{O}$ pietismo, que se desenvolveu especialmente na Alemanha na segunda metade do século XVII e cujo chefe foi Filipe Jacó Spener (1635-1705), pretendia voltar às teses originárias da Reforma protestante, sobretudo a livre interpretação da Bíblia e a negação da teologia. Teve importante ligação com o Iluminismo.

${ }^{2}$ Cf. BOROWSKI, L. E.; JACHMANN, R. B.; WASIANKI, E. A. Kant Intime. Paris: Bernard Grasset, 1985 , p. 35.

${ }^{3}$ Cf. PASCAL, Georges. O Pensamento de Kant. Petrópolis: Vozes, 1985, p. 14.

4 "Assim, na execução do plano que a crítica prescreve, i. e., no futuro sistema da metafísica, temos de seguir a partir de agora o método estrito do famoso Wolff, o maior entre todos os filósofos dogmáticos, que foi o primeiro a dar o exemplo (e se tornou por esse exemplo o fundador do espírito de rigor até hoje não extinto na Alemanha) de como se deve tomar o caminho seguro de uma ciência por meio do legítimo estabelecimento dos princípios, da clara determinação dos conceitos, da busca de rigor nas provas e da prevenção de saltos audaciosos nas inferências, (...)" (CRP, B XXXVI).

${ }^{5}$ Cf. BOUTROUX, Émile. Kant. Lisboa: Inquérito, 1983, p. 14.
} 
Em 1770, com a Dissertação sobre a Forma e os Princípios do mundo sensível e do mundo inteligível, Kant conquista o posto de Professor Titular na Universidade de Königsberg. Desde então, preleciona lógica e metafísica, no curso público, e direito natural, moral, teologia natural, antropologia, geografia física, matemática, pedagogia, nos seus cursos privados. Após a Dissertação de 1770, Kant é absorvido pelo problema da crítica do conhecimento humano, mas levará mais de dez anos para dar forma à sua filosofia. Assim, em 1781, em Riga, faz publicar a Crítica da razão pura, um dos monumentos do espírito humano. Em 1788, surge a Crítica da razão prática. Com a publicação da Crítica do juízo (1790), a filosofia kantiana pode considerar-se completa.

A partir de 1790 suas forças começaram a declinar e em 1797 deixou a cátedra. Continuou a escrever e trabalhou até os últimos dias numa obra inacabada em que queria explicar a passagem da metafísica da ciência da natureza à física. Morreu num domingo, em 12 de fevereiro de 1804, às onze horas. A sua última frase foi: "Es ist gut" (está bem).

As obras de Kant podem ser classificadas, distinguindo-se três períodos:

1) De 1755 a 1770. Neste período, as ideias pessoais de Kant ainda não haviam tomado forma. Comunga das ideias filosóficas predominantes na Alemanha, a saber, o racionalismo dogmático de Leibniz, tal como fora desenvolvido e divulgado por Wolff. Entretanto, como o próprio Kant declara no prefácio aos Prolegômenos, a leitura de Hume pôs fim a seu "sono dogmático"6.

2) De 1770 a 1790 . É só em 1770 que se começa a divisar um primeiro esboço da filosofia kantiana. Com efeito, na Dissertação de 1770 já se estabelece a distinção entre o mundo dos fenômenos e o mundo dos númenos, como resultado de uma concepção inteiramente original do espaço e do tempo ${ }^{7}$ Entre 1780 e 1790 vêm a lume as grandes obras de Kant, aquelas que caracterizam o criticismo: Crítica da razão pura (1781), Prolegômenos (1783), Fundamentação da Metafísica dos Costumes (1785), Crítica da razão prática $(1788)^{8}$. De notar-se que Kant, na Crítica da razão pura, divide a filosofia em duas partes. A primeira, propedêutica, se encarrega de investigar a capacidade da razão concernente a todo conhecimento a priori. Esta parte se chama crítica. A segunda é o sistema da razão pura e apresenta o conhecimento filosófico dela derivado como um conjunto sistemático. Esta parte se denomina metafísica e se subdivide em metafísica do uso especulativo da razão (metafísica da natureza) e metafísica do uso prático da razão (metafísica dos costumes). ${ }^{9}$ Destarte, a faculdade completa da razão pura está subordinada à tarefa crítica, que é desenvolvida nas duas primeiras Críticas. A Crítica da razão pura responde à pergunta sobre a possibilidade dos juízos sintéticos a priori no uso especulativo e fundamenta a metafísica da natureza. A Crítica da razão prática trata da possibilidade desses juízos no uso prático e embasa a metafísica dos costumes ${ }^{10}$.

\footnotetext{
${ }^{6}$ Prolegomena, Bd. 5, p. 118 (A 12, 13).

${ }^{7}$ Cf. PASCAL, 1985, p. 16. Como veremos, Kant procura demonstrar que o espaço e o tempo derivam da experiência de objetos particulares, uma vez que esta experiência os pressupõe, concluindo que ambos são formas a priori da sensibilidade.

${ }^{8}$ A Crítica da razão pura estava dedicada ao estudo do sujeito cognoscente. A Crítica da razão prática se dedicará ao estudo do sujeito moral definido pela liberdade. No Prefácio da Crítica da razão prática, Kant assinala que o fim essencial dessa obra é estabelecer a existência de uma razão pura prática e, a partir dela, a existência da liberdade transcendental. Isto porque, para Kant, se não houvesse a liberdade, não existiria a lei moral em nós; se não conhecêssemos a lei moral, desconheceríamos a liberdade.

${ }^{9}$ A Metafísica da Natureza concerne aos princípios a priori do conhecimento empírico da natureza e dos objetos físicos em geral. A Metafísica dos Costumes concerne aos princípios a priori dos juízos morais em geral.

${ }^{10}$ Cf. PROBERT, Dulce María Granja Castro de. Estudio Preliminar. In: KANT, Immanuel. Crítica de la Razón Práctica. México: FCE, UAM, UNAM, 2005, p. XIII-XIV.
} 
3) De 1790 a 1800. A Crítica do juízo, mantendo de pé as premissas fundamentais da filosofia kantiana, confirma a postura contra a metafísica dogmática e o empirismo cético, contida na Crítica da razão pura e na Crítica da razão prática, encerrando a obra crítica e estabelecendo uma doutrina de filosofia especulativa e moral. Após 1790, outras obras fundamentais, que não alterarão o fio condutor do pensamento kantiano, serão publicadas: A religião dentro dos limites da simples razão (1793), À Paz Perpétua (1795), A Metafísica dos Costumes (1797), Antropologia do ponto vista pragmático (1798), Lógica (1800).

\section{A Gênese do Idealismo}

O criticismo kantiano - que culmina no idealismo transcendental - é a confluência de duas direções fundamentais do pensamento filosófico: o racionalismo dogmático (Descartes - Spinoza - Leibniz - Wolff) e o empirismo cético (Bacon Locke - Hume $)^{11}$. Para o racionalismo, o conhecimento seria produto de uma simples faculdade: a razão. Para o empirismo, o conhecimento derivaria de outra faculdade: a sensibilidade.

Kant, que se educou sob a influência do racionalismo de Wolff, declara que o ceticismo de Hume o fez despertar do seu sono dogmático e deu às suas investigações no caminho da filosofia especulativa uma orientação totalmente diversa, impelindo-o a indagar sobre as condições e os limites do conhecimento humano, bem assim suas possibilidades $^{12}$.

Destarte, Kant diferencia a filosofia das ciências, pois, enquanto cada uma destas últimas tem objeto próprio, o objeto da filosofia é o conhecimento mesmo, a análise da ciência ${ }^{13}$. Por esta via, o criticismo permite chegar à conclusão de que o conhecimento é produto de uma faculdade complexa, o resultado de uma síntese da sensibilidade e do entendimento. ${ }^{14}$

Para isto, começa por dizer que todo conhecimento implica uma relação melhor: uma correlação - entre um sujeito e um objeto. Nessa relação, os dados objetivos não são captados por nossa mente tais quais são (a coisa em si), mas configurados pelo modo com que a sensibilidade e o entendimento os apreendem. Assim, a coisa em si, o númeno, o absoluto, é incognoscível.

Só conhecemos o ser das coisas na medida em que se nos aparecem, isto é, enquanto fenômeno. Mas, como atuam no conhecimento dos fenômenos a sensibilidade e o entendimento do sujeito cognoscente? Aqui, Kant recorre a uma distinção

\footnotetext{
${ }^{11}$ Como sublinha Jonathan Bennett, essas duas tradições filosóficas juntam-se na filosofia kantiana não como uma mescla inconsistente, mas como uma síntese coerente de verdades extraídas de cada uma delas (cf. La Crítica de la Razón Pura de Kant, 2, Dialéctica, p. 21).

12 Prolegomena, Bd. 5, p. 118 (A 12, 13). Will Dudley afirma que a causa filosófica imediata do Idealismo alemão foi o ceticismo de Hume e que o ataque ao princípio da causalidade, que leva mais diretamente ao ceticismo e ao determinismo, é o que inspira o desenvolvimento e a defesa da alternativa ao empirismo que o Idealismo alemão começa (Idealismo alemão, 2013, p. 14 e 19).

${ }^{13}$ A filosofia moderna - especialmente a partir de Kant - conquistou seu objeto e método próprio, de tal modo que, ao mesmo tempo em que se constitui como conhecimento rigoroso, separou-se das ciências particulares, evitando toda superposiçao recíproca de métodos e objetos. Enquanto as ciências, na atitude dogmática, ocupam-se de seus objetos próprios, a filosofia ocupa-se das ciências mesmas e do conhecimento. Este é o segredo do ceticismo metódico de Descartes e depois do criticismo de Kant (Cf. nosso: LEITE, Flamarion Tavares. "O cogito em Kant e Husserl”. Revista Brasileira de Filosofia, vol. XXXIX, fasc. 166, São Paulo, 1992, p. 141).

${ }^{14}$ Como observa Kant, existem dois troncos do conhecimento humano: a sensibilidade e o entendimento. Através da primeira se nos dão os objetos. Através da segunda, os pensamos (cf. $\mathrm{Kr} V$, Transzendentale Ästhetik, § 1, Bd. 3, p. 69) (B 33).
} 
fundamental, segundo a qual todo fenômeno, tudo quanto existe, inclusive o conhecimento, se integra por dois ingredientes: matéria e forma ${ }^{15}$.

Aquilo que depende do próprio objeto constitui a matéria do conhecimento. $\mathrm{O}$ que depende do sujeito constitui a forma do conhecimento. Assim, temos uma primeira definição: conhecer é dar forma a uma matéria dada. A matéria é a posteriori. A forma é a priori. A matéria do conhecimento é variável de um objeto a outro, visto depender dele, do objeto. Por sua vez, a forma, sendo imposta ao objeto pelo sujeito, será reencontrada invariavelmente, em todos os objetos, por todos os sujeitos. Existem, pois, conhecimentos a priori e conhecimentos a posteriori. Todo objeto a ser conhecido $a$ priori o será conforme as formas que o espírito lhe impõe no ato de conhecer.

Como corolário dos conhecimentos a priori, os juízos podem ser analíticos aqueles em que o predicado constitui uma representação ou explicitação do que já se encontra no sujeito (todos os corpos são extensos) - ou sintéticos - aqueles cujo predicado acrescenta alguma coisa ao conceito do sujeito (todos os corpos são pesados). Todo juízo de experiência é sintético, porque a experiência nos ensina a acrescentar certos atributos aos nossos conceitos (o peso ao conceito de corpo).

Os juízos analíticos são a priori, pois não há necessidade de recorrer à experiência para determinar o que pensamos num dado conceito (todos os solteiros não são casados). Os juízos sintéticos são a posteriori, porque supõem a descrição de experiências particulares observáveis. Demais disso, um juízo é analítico quando sua negação constitui contradição, ou seja, é logicamente impossível. Inversamente, o juízo sintético é aquele cuja negação não supõe contradição.

Mas a grande descoberta de Kant é a da existência de uma terceira classe de juízos: os juízos sintéticos a priori, que são universais e necessários, como os analíticos e, no entanto, permitem ampliar nossos conhecimentos. É aos juízos sintéticos a priori que a matemática e a física devem o seu caráter de certeza. O problema é saber se tais juízos são possíveis em metafísica ${ }^{16}$.

Feita a distinção entre matéria e forma, Kant caracteriza as formas a priori do espírito. Por formas a priori devem-se entender os quadros universais e necessários através dos quais o espírito humano percebe o mundo. Assim sendo, distinguem-se, em nossa faculdade de conhecer, uma receptividade (a sensibilidade ou faculdade das intuições) e uma espontaneidade (o entendimento ou faculdade dos conceitos). O objeto, dado à sensibilidade, é pensado pelo entendimento e seus conceitos. Temos uma segunda definição: conhecer é ligar em conceitos a multiplicidade sensível ${ }^{17}$.

As formas a priori da sensibilidade ou intuições puras são o espaço e o tempo,

\footnotetext{
${ }^{15}$ Cf. AFTALIÓN, Enrique R., OLANO, Fernando García, VILANOVA, José. Introducción al derecho. Buenos Aires: Cooperadora de Derecho y Ciencias Sociales, 1972, p. 839.

16 Kant afirma que a quase totalidade das proposições da matemática, que não é uma ciência experimental, consiste de juízos sintéticos a priori e que esses juízos constituem os pressupostos fundamentais das ciências naturais e do pensamento moral. "A resposta de Kant ao ceticismo de Hume no que se refere à possibilidade da metafísica diz respeito a se ela pode ou não produzir conhecimento sintético a priori sem cair de volta no racionalismo dogmático. A metafísica precisa ser a priori porque ela procura verdades necessárias e universais, enquanto o conhecimento a posteriori pode oferecer somente generalizações contingentes. A experiência pode nos dizer como o mundo é, mas não como ele precisa ser. E a metafísica precisa ser sintética porque ela procura nos informar sobre o mundo, enquanto os julgamentos analíticos nos informam somente sobre os significados dos nossos conceitos. A principal tarefa da Crítica da razão pura é determinar as condições de possibilidade da experiência e, por decorrência, restaurar e completar a metafísica como uma rigorosa disciplina filosófica, capaz de resistir e responder ao escrutínio de Hume. Kant denomina as condições que tornam a experiência possível de 'transcendentais' e o exame destas condições de 'filosofia transcendental'" (Cf. DUDLEY, Will. Idealismo alemão. Petrópolis, RJ: Vozes, 2013, p. 35).

${ }^{17} \mathrm{KrV}$, Transzendentale Logik, Einleitung, I, Bd. 3, p. 97-98 (B 74,75); e, ainda: PASCAL, 1985, p. 40.
} 
que tornam exequível a parte passiva do conhecimento. As formas a priori do entendimento são as categorias, as quais possibilitam a parte ativa do conhecer: as operações lógicas, a formação de conceitos, com os quais se podem imaginar os objetos sem necessidade de captá-los concretamente. A intuição permite tomar contato com as coisas, porém só é possível dar conta de suas diferenças por meio de conceitos.

As formas da razão são as ideias. Enquanto os conceitos, para valer como conhecimento, devem estruturar-se sobre o material que fornecem as intuições, a razão tem uma tendência para ultrapassar os limites do conhecimento. ${ }^{18}$ Ao transpor as fronteiras da sensibilidade e buscar o incondicionado, a razão penetra num mundo puramente inteligível. Estaremos no mundo das ideias, não no conhecimento de objetos; não em presença de fenômenos determinados, mas de númenos, acerca dos quais não se pode cogitar de experiência possível.

No afã de buscar o incondicionado, a razão incorre em erros ou paralogismos e, no seu discurso dialético, em antinomias. ${ }^{19}$ Kant estuda as antinomias da razão pura na dialética transcendental, tornando-se patente no terceiro conflito $^{20}$ das ideias transcendentais a causalidade por liberdade, de onde surgirá, fora dos limites da experiência, a ideia moral e concepção ética que se traduzirão na Fundamentação da Metafísica dos Costumes e na Crítica da razão prática. A terceira antinomia trata da oposição entre liberdade e necessidade da natureza, cuja solução abre o espaço de possibilidade para a reflexão prática. O exame da liberdade será objeto da Crítica da razão prática, através da realidade da obrigação moral. Assim, o exercício da liberdade é condição necessária da ação moral ${ }^{21}$.

De fato, se a razão teórica, em sua dialética transcendental, nos faz vislumbrar o caminho de uma causalidade por liberdade, trata-se, com a razão prática, de penetrar o mundo moral - universo inteligível, distinto da natureza. É a liberdade que abre este cosmos, onde a razão, agora autodeterminante, é vontade produtora de seus próprios objetos - sem necessidade de vinculá-los aos sentidos - e de suas próprias leis, posto que autônoma.

Por isso, cabe distinguir as ideias da razão teórica ou cognoscitiva das ideias da razão prática ou atuante, que se refere à conduta, ao agir propriamente dito. As ideias da razão teórica não podem ser resolvidas no plano teorético, científico. Entretanto, se a metafísica, enquanto conhecimento teórico não se pode realizar, diversamente se dá quando se trata da filosofia prática, onde as ideias são princípios de ação, ocupando-se a razão dos princípios determinantes da vontade, tendo a ideia de liberdade por fundamento.

\footnotetext{
${ }^{18}$ Cf. AFTALIÓN; OLANO; VILANOVA, 1972. p. 842.

19 As antinomias examinadas por Kant são quatro e têm sua origem no fato de se considerarem os fenômenos como coisas em si, aplicando-se a eles o princípio de que o condicionado exige a totalidade incondicionada das suas condições. As antinomias somente serão resolvidas se se distinguirem os fenômenos das coisas em si.

${ }^{20}$ Kant dá especial atenção à terceira antinomia, que diz respeito ao problema da liberdade. A tese diz: "A causalidade segundo as leis da natureza não é a única a partir da qual os fenômenos do mundo possam ser deduzidos em seu conjunto. Para explicá-los é também necessário admitir uma causalidade por meio da liberdade." A antítese rebate: "Não há liberdade, e tudo no mundo acontece segundo as leis da natureza." (CRP, B 472/473, p. 377). Kant apresenta a solução desta antinomia ao afirmar que se os fenômenos fossem coisa em si não se poderia salvar a liberdade, porque para eles vige o determinismo. Mas se não são coisa em si, devem ter causas que não são fenômenos. E essas causas podem ser causas livres.

${ }^{21}$ Depois de estudar as obras de Kant, Fichte impressionou-se principalmente pela afirmação da liberdade e numa carta a Achelis do final de 1790 escreve: "Devo confessar-lhe que agora acredito plenamente na liberdade do homem, e vejo claramente que só pressupondo a liberdade é possível o dever, a virtude e, em geral, uma moral" (citado por Medicus, I, p. 23, apud ROVIGHI, Sofia Vanni. História da Filosofia Moderna: da revolução científica a Hegel. São Paulo: Loyola, 1999, p. 634-635).
} 
Assinale-se que o conceito de liberdade em Kant não é entendido como um querer determinado pela sensibilidade. Chega-se à liberdade por constrição do mundo causal. Esta liberdade é encontrada na razão prática, isto é, na vontade. Assim, a liberdade pode ser explicada a partir do conceito de vontade.

De lembrar-se que o conceito de liberdade já havia sido anunciado na Dialética Transcendental, da primeira Crítica, nas antinomias da razão pura, como causalidade por liberdade ${ }^{22}$. Há, de fato, que se considerar que o homem aparece como fenômeno na Natureza e, como tal, sujeito à lei de causalidade natural. De outro lado, deve-se considerá-lo como númeno - do ponto de vista prático -, vale dizer, um ente inteligível capaz de lembrar sua própria causa, sem nenhum constrangimento exterior que não seja a sua própria vontade ${ }^{23}$. Esta autossuficiência implica sua liberdade. E esta liberdade que vai engendrar um mundo distinto do natural - o mundo moral.

A liberdade é, pois, um conceito que se torna a pedra angular de todo o edifício do sistema kantiano, na medida em sua realidade é demonstrada por uma lei apodítica da razão prática. Daí Kant asseverar que os outros conceitos (os de Deus e da imortalidade da alma), enquanto simples ideias, permanecem no âmbito da razão especulativa sem apoio, só adquirindo consistência e realidade objetiva quando conectados com o conceito de liberdade, a qual se revela mediante a lei moral ${ }^{24}$.

Desta forma, manifestada pela lei moral, a liberdade está reconhecida na sua realidade. Conhece-se a priori a sua possibilidade, porque ela é a condição da lei moral. É nestas condições que o homem, simples fenômeno, alcança a sua condição de númeno $^{25}$. Isto porque, como aponta Soraya Nour, do ponto de vista numênico pensamo-nos como seres livres, membros de um mundo inteligível, no qual reconhecemos a autonomia da liberdade e seu efeito, a moralidade; mas do ponto de vista fenomênico, compreendemo-nos como membros do mundo sensível e do mundo inteligível $^{26}$.

\section{O Idealismo Alemão}

O idealismo alemão surgiu em 1781, com a publicação da Crítica da razão pura, de Kant, e terminou cinquenta anos mais tarde com a morte de $\mathrm{Hegel}^{27}$. O florescimento

\footnotetext{
${ }^{22}$ A Crítica da razão prática retoma um resultado da Crítica da razão pura, dando-lhe uma determinação que só é possível no domínio prático. A ideia de liberdade é um conceito da razão teórica, a qual, em seu afã de chegar a explicações últimas, é levada a admitir a possibilidade de uma causalidade livre e incondicional.

${ }^{23}$ Como lembra Kant, "só pudemos defender o pensamento de uma causa agindo livremente, por termos mostrado que não se contradiz considerar todas as suas ações como fisicamente condicionadas, na medida em que são fenômenos, e ainda assim ao mesmo tempo considerar a causalidade das mesmas, na medida em que o agente é um ser inteligível, como fisicamente incondicionada" (CRPr, A 84).

${ }^{24} \mathrm{CRPr}$, A 5,6).

25 "A reunião da causalidade como liberdade com a causalidade enquanto mecanismo da Natureza, estabelecendo-se a primeira pela lei moral e a segunda mediante a lei natural, num só e mesmo sujeito, o homem, é impossível, sem representar este, em relação à primeira, como ser em si mesmo, mas relativamente à segunda como fenômeno, aquele na consciência pura, este na consciência empírica. Sem isso é inevitável a contradição da razão consigo mesma" (CRPr, A 9,10 - Nota de Kant).

${ }^{26}$ Cf. NOUR, Soraya. À paz perpétua de Kant: filosofia do direito e das relações internacionais. São Paulo: Martins Fontes, 2004, p. 19-20.

${ }^{27}$ Cf. DUDLEY, 2013, p. 13. O idealismo alemão abrange um arco que se estende de Kant a Hegel, passando pelos românticos (Schlegel, Novalis, Schleiermacher, Hölderlin, Schiller, Goethe) e por Fichte e Schelling, dentre outros. Os pensadores desse período, bem como os temas que desenvolveram, revolucionaram a filosofia e tiveram impacto, até hoje sentido, nas ciências humanas e sociais. Kant, Fichte, Schelling e Hegel - os mais importantes idealistas alemães - sedimentaram o caminho para Marx, Kierkegaard, a fenomenologia, o existencialismo, a teoria crítica e o pós-estruturalismo.
} 
filosófico ${ }^{28}$ que a Alemanha vive no contexto cultural que abarca o meio século que vai de 1780 a $1830^{29}$ resulta no idealismo alemão, fundado por Kant, desenvolvido por Fichte e Schelling e levado à culminância especulativa por Hegel.

O nome idealismo alemão é atribuído por conta da índole de sua postura filosófica, em consequência da revolução copernicana ${ }^{30}$ realizada por Kant no campo da teoria do conhecimento, bem como ao seu idealismo transcendental, frente ao realismo anterior próprio do pensamento antigo e medieval ${ }^{31}$. A crítica kantiana ao conhecimento aponta o contraste entre os contínuos progressos da ciência físicomatemática e os claudicantes passos da metafísica.

De fato, tornou-se moda à época de Kant testemunhar o maior desprezo àquela que antes era chamada a rainha de todas as ciências e "a nobre dama, repudiada e desamparada, lamenta-se como Hécuba: modo maxima rerum, tot generis natisque potens - nunc trahor exul, inops (Ovídio, Metamorfoses)" "32. Para Kant, impõe-se aplicar à metafísica o método a priori que apresentou exitoso resultado na física e na matemática, garantindo-lhes o seguro caminho da ciência.

A aplicação deste método ao problema do conhecimento conduz à revolução copernicana, cuja denominação se deve ao fato de que Kant toma como analogia a mudança introduzida por Copérnico na concepção do sistema solar ${ }^{33}$. Essa revolução, em Kant, significa a substituição da hipótese realista pela hipótese idealista. O realismo admite que uma realidade nos é dada, seja de ordem inteligível (racionalismo), seja de ordem sensível (empirismo), e que o nosso conhecimento deve modelar-se sobre essa realidade.

\footnotetext{
${ }^{28}$ Este florescimento não se deu apenas na filosofia, mas também nas letras, na música, na filologia e na historiografia.

${ }^{29}$ Nesse contexto, desenvolve-se na Universidade de Jena, durante mais de duas décadas, e, depois da batalha de 1806, na Universidade de Berlim, o grupo de filósofos designados por idealistas alemães. O ponto de partida para todos eles é a filosofia kantiana, cuja inesgotável riqueza produz novas tentativas de solução para os problemas propostos (Cf. HARTMANN, Nicolai. A filosofia do idealismo alemão. Lisboa: Calouste Gulbenkian, 1983, p. 9).

${ }^{30}$ No Prefácio à Crítica da razão pura, Kant afirma sua pretensão de fazer uma revolução copernicana na epistemologia, pois julga que somente ela pode salvar a metafísica do racionalismo dogmático e do empirismo cético. Esta revolução é iniciada com a redefinição da classificação de Hume, que admite apenas dois tipos de conhecimento: a relação das ideias e as questões de fato. A estes Kant opõe, como vimos acima, os conhecimentos a priori, a posteriori e os juízos analíticos, sintéticos e sintéticos a priori.

${ }^{31}$ Cf. TRUYOL Y SERRA, Antonio. Historia de la filosofía del derecho y del estado. Madrid: Alianza, 1982. v. 2, p. 10.

32 "Ainda há pouco a maior de todas, poderosa entre tantos genros e filhos - e agora exilada, enfraquecida." Citado por Kant em Crítica da Razão Pura, Prefácio à Primeira Edição (1781), A IX, 2012, p. 17. (Cf. Metamorfoses, "O sacrifício de Políxena e a metamorfose de Hécuba, sua mãe", Livro XIII, 429-575). Bocage traduz: "Dantes tantas grandezas possuindo,/Tantos genros, e filhos, c'roa, esposo,/Hoje em desterro, na indigência agora (OVÍDIO. Metamorfoses. São Paulo: Martin Claret, 2006, p. 104).

33 “Até hoje se assumiu que todo nosso conhecimento teria de regular-se pelos objetos; mas toda tentativa de descobrir algo sobre eles a priori, por meio de conceitos, para assim alargar nosso conhecimento, fracassaram sob essa pressuposição. É preciso verificar pelo menos uma vez, portanto, se não nos sairemos melhor, nas tarefas da metafísica, assumindo que os objetos têm de regular-se por nosso conhecimento, o que já se coaduna melhor com a possibilidade, aí visada, de um conhecimento a priori dos mesmos, capaz de estabelecer algo sobre os objetos antes que nos sejam dados. Isso guarda uma semelhança com os primeiros pensamentos de Copérnico, que, não conseguindo avançar muito na explicação dos movimentos celestes sob a suposição de que toda a multidão de estrelas giraria em torno do espectador, verificou se não daria mais certo fazer girar o espectador e, do outro lado, deixar as estrelas em repouso. Pode-se agora, na metafísica, tentar algo similar no que diz respeito à intuição dos objetos." (CRP, B XVI/XVII, p. 29-30).
} 
Assim, conhecer é simplesmente registrar o real, e a nossa mente, nesta operação, é meramente passiva. O idealismo considera que a nossa mente intervém ativamente na elaboração do conhecimento e que o real, para nós, é resultado de uma construção. O objeto, tal como o conhecemos é, em parte, obra nossa e, portanto, podemos conhecer a priori, em relação a todo objeto as características que ele recebe da nossa própria faculdade cognitiva ${ }^{34}$.

A revolução copernicana abriu o pensamento kantiano para uma dimensão inédita do conhecimento: a do conhecimento transcendental e a priori. Kant define o termo transcendental ao afirmar: "Eu denomino transcendental todo conhecimento que se ocupe não tanto com os objetos, mas com o nosso modo de conhecer os objetos, na medida em que estes devam ser possíveis a prior" ${ }^{i 5}$. Assim, transcendental é o que torna possível um conhecimento a priori.

E idealismo transcendental é a doutrina segundo a qual todo objeto de conhecimento é determinado a priori pela própria natureza da nossa faculdade de conhecer $^{36}$ Isto não quer dizer, entretanto, que Kant duvide da existência das coisas fora de nós - como o idealismo clássico -, mas que os objetos não são conhecidos senão através das formas que a nossa faculdade de conhecer lhes impõe. Destarte, o seu idealismo não é ontológico, pois não se refere à existência ou à natureza das coisas, mas à nossa maneira de conhecê-las, sendo, pois, um idealismo gnosiológico e crítico, ao admitir a independência das coisas em relação à consciência, mas postulando que estão condicionadas pelas formas a priori da consciência. O conhecimento objetivo exige, pois, como condição de possibilidade, os elementos a priori da faculdade de conhecer. Assim, não há objeto senão para um sujeito, consumando-se a revolução copernicana, posto que, agora, os objetos do conhecimento são regidos pelo sujeito. A unidade do objeto tem origem na unidade da consciência, ou seja, no eu penso. $\mathrm{O}$ eu penso consiste no ato de restituir à unidade da apercepção a síntese do diverso dado na intuição, devendo-se notar que apercepção é um termo de Leibniz. À relação entre o sujeito e a diversidade de representações, que o eu penso deve ser capaz de acompanhar ${ }^{37}$, Kant

\footnotetext{
34 "Nós só podemos conhecer a priori das coisas aquilo que nós mesmos nelas colocamos" (CRP, Prefácio, B XVIII, p. 31).

${ }^{35} C R P$, B 25, p. 60. Manuela Pinto dos Santos e Alexandre Fradique Morujão traduzem: "Chamo transcendental a todo o conhecimento em geral que se ocupa menos dos objectos, que do nosso modo de os conhecer, na medida em que este deve possível a priori” (CRP, p. 53, ed. Calouste Gulbenkian, 1985). ${ }^{36}$ CRP, B 80-81, p. 99-100; Cf. também: PASCAL, 1985, p. 44. Ver ainda: LEITE, Flamarion Tavares. 10 Lições sobre Kant. 9. ed. Petrópolis: Vozes, 2015, p. 18, onde, discutindo a oposição racionalismoempirismo, afirmamos: o idealismo transcendental é aquela posição filosófica que resolve "judicialmente" as disputas nascidas em torno das pretensões da razão de possuir determinados conceitos legitimamente - de não havê-los usurpado -, afirmando que tese e antítese são verdadeiras, desde que sejamos capazes de assumir a perspectiva que faz verdadeira uma e outra. Permanecer aprisionado em uma só delas conduz irrevogavelmente a antinomias.

37 "O eu penso deve poder acompanhar todas as minhas representações; se assim não fosse, algo se representaria em mim que não poderia, de modo algum, ser pensado, que o mesmo é dizer, que a representação ou seria impossível ou pelo menos nada seria para mim. A representação que pode ser dada antes de qualquer pensamento chama-se intuição. Portanto, todo o diverso da intuição possui uma relação necessária ao eu penso, no mesmo sujeito em que esse diverso se encontra. Esta representação, porém é um ato da espontaneidade, isto é, não pode considerar-se pertencente à sensibilidade. Dou-lhe o nome de apercepção pura, para a distinguir da empírica ou ainda o de apercepção originária, porque é aquela autoconsciência que, ao produzir a representação eu penso, que tem de poder acompanhar todas as outras, e que é una e idêntica em toda a consciência, não pode ser acompanhada por nenhuma outra. Também chamo à unidade dessa representação a unidade transcendental da autoconsciência, para designar a possibilidade do conhecimento a priori a partir dela" (CRP, § 16, B 131-132, 1985, p. 131-132). Ainda sobre o eu penso, Cf. LEITE, 1992, p. 135.
} 
chama de apercepção pura ou apercepção originária, contrapondo-se ao sentido que apercepção tinha para Leibniz ${ }^{38}$.

É noção cediça que o eu penso converte-se na pedra angular das correções que Kant estabeleceu entre a primeira edição (1781) e a segunda edição (1787) da Crítica da razão pura. De fato, na primeira edição a apercepção pura é definida como "o eu estável e permanente que constitui o correlato de todas as nossas representações, com respeito à simples possibilidade de ter consciência delas"; desta forma, "todo o conhecimento pertence a uma apercepção pura e omnicompreensiva, assim como toda a intuição sensível, enquanto representação, pertence a uma intuição pura interna, isto é, ao tempo." Na segunda edição, o caráter subjetivo da unidade transcendental ${ }^{39}$ é definido principalmente em relação à sua pura formalidade, por meio do contraste, que se repete frequentemente, com o caráter intuitivo de uma problemática inteligência divina.

Mas se o eu estável e permanente ( $1^{\mathrm{a}}$ edição) é uma realidade psicológica, o eu formal ( $2^{\mathrm{a}}$ edição) não passa de uma possibilidade originária da unificação da experiência. Nas considerações repetidas através dos parágrafos 16, 17, 21, da Crítica da razão pura, Kant insiste no caráter finito do entendimento humano e do ato originário em que se exprime. Se na primeira edição a dedução $o^{40}$ conduzia ao eu penso, na segunda partirá dele. Por isso, o eu penso constitui não apenas o núcleo do pensamento kantiano, o princípio supremo do conhecimento (nada pode ser conhecido se não estiver em relação com o eu penso), mas, sobretudo, o ápice do subjetivismo moderno.

O sujeito já não é - como em Descartes - simples ponto de partida, mas se converteu em centro (sua percepção constitui os objetos). Vê-se que é inevitável retornar à problemática cartesiana quando se pretende falar do cogito (eu penso). Com efeito, é no filósofo francês que vamos encontrar uma preocupação inicial com o cogito (sob a forma cogito ergo sum) que iria ser desenvolvida mais tarde - embora com alcance distinto - por Kant.

Todavia, entre o cogito cartesiano e o cogito kantiano há uma diferença radical. Enquanto em Descartes, para o acesso à realidade em si, há que se estabelecer um critério de certeza com base na intuição - a apreensão de mim por mim -, em Kant o conhecimento das coisas torna-se verdadeira condição do conhecimento de si: não me conheço, senão conhecendo as coisas.

O eu penso acompanha todas as minhas representações, mas, diversamente do cogito cartesiano, ele não pode se destacar delas e tornar-se para si mesmo seu próprio objeto. Deste modo, se Descartes significa historicamente a juventude, Kant significa a maturidade do moderno subjetivismo. Depois dele só poderia vir a orgia romântica de Fichte: o eu como auto posição ${ }^{41}$.

\footnotetext{
${ }^{38}$ Apercepção é um termo introduzido por Leibniz para designar a apreensão reflexiva que a mente tem de seus próprios estados internos, ou seja, consciência das próprias percepções. Para Kant essa é a apercepção empírica que deve ser distinguida da apercepção pura. A apercepção pura ou transcendental é o eu penso que deve poder acompanhar todas as minhas representações (CRP, § 16).

39 "A unidade transcendental da apercepção é aquela pela qual todo o diverso dado numa intuição é reunido num conceito do objeto" (CRP, § 18).

${ }^{40}$ Trata-se da dedução transcendental dos conceitos puros do entendimento ou das categorias (CRP, § 15 ss.).

${ }^{41}$ COLOMER, Eusebi. El pensamiento alemán de Kant a Heidegger. Barcelona: Editorial Herder, 1986. v. 1, p. 121.
} 


\section{Considerações Finais}

De tudo o que precedentemente se explicitou, podemos inferir que o idealismo alemão se desenvolveu a partir da refutação kantiana do empirismo cético de Hume, bem como do determinismo. Como vimos, a pretensão de Kant era a de salvar a racionalidade e a liberdade, empregando o método transcendental no seu exame crítico do processo de conhecimento que culmina no idealismo transcendental, para o qual os objetos da experiência devem se conformar às nossas condições cognitivas, que se limitam às aparências (fenômeno), sendo a coisa em si (númeno) totalmente inacessível a nós.

Mas, a razão pretende conhecer o incondicionado e, ao intentá-lo, se perde em paralogismos e antinomias. A terceira antinomia trata da oposição entre liberdade e necessidade da natureza, cuja solução abre o espaço de possibilidade para a reflexão prática.

O exame da liberdade será objeto da Crítica da razão prática, através da realidade da obrigação moral. Isto porque se a razão teórica nos faz perceber o caminho de uma causalidade por meio da liberdade, trata-se, com a razão prática, de penetrar o mundo moral. É a liberdade que abre este cosmos, onde a razão, agora autodeterminante, é vontade produtora de seus próprios objetos e de suas próprias leis, posto que autônoma.

Com a Crítica da razão pura e a Crítica da razão prática, Kant refuta tanto o empirismo cético como o determinismo de Hume, opondo ao primeiro a sua revolução copernicana e o idealismo transcendental, e ao segundo o fato de que não obstante tenhamos eventos sujeitos à necessidade causal, isto não obstaculiza a possibilidade de que algum evento seja produto da liberdade. Esta refutação será, pois, a base do idealismo alemão, cujos desdobramentos ocorrerão nas filosofias de Fichte, Schelling e Hegel.

\section{Referências}

AFTALIÓN, Enrique R., OLANO, Fernando García, VILANOVA, José. Introducción al derecho. Buenos Aires: Cooperadora de Derecho y Ciencias Sociales, 1972.

BENNETT, J. La Crítica de la Razón Pura de Kant, 2, La Dialéctica. Madrid: Alianza, 1981. BOROWSKI, L. E.; JACHMANN, R. B.; WASIANKI, E. A. Kant Intime. Paris: Bernard Grasset, 1985.

BOUTROUX, Émile. Kant. Lisboa: Inquérito, 1983.

COLOMER, Eusebi. El pensamiento alemán de Kant a Heidegger. Barcelona: Editorial Herder, 1986. v. 1.

DUDLEY, Will. Idealismo alemão. Petrópolis, RJ: Vozes, 2013.

HARTMANN, Nicolai. A filosofia do idealismo alemão. Lisboa: Calouste Gulbenkian, 1983.

KANT, Immanuel. Crítica da Razão Pura. Petrópolis: Vozes; Bragança Paulista: Editora Universitária São Francisco, 2012.

Crítica da Razão Pura. Lisboa: Fundação Calouste Gulbenkian, 1985.

Crítica da Razão Prática. São Paulo: Martins Fontes, 2003.

. Crítica de la Razón Práctica, México, FCE, UAM, UNAM, 2005.

Werke in Zehn Bänden, Darmstadt, hrsg. Von Wilhelm Weischedel, Wissenschaftliche Buchgesellschaft, 1956: Band 3: Kritik der reinen Vernunft, Erster Teil. 4: Kritik der reinen Vernunft, Zweiter Teil. 5: Prolegomena. Logik.

LEITE, Flamarion Tavares. "O cogito em Kant e Husserl”. Revista Brasileira de Filosofia, vol. XXXIX, fasc. 166, São Paulo, 1992.

10 Lições sobre Kant. 9. ed. Petrópolis, RJ: Vozes, 2015.

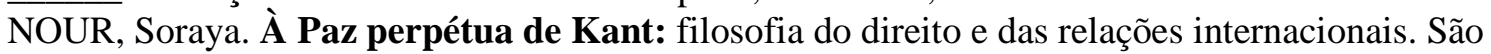
Paulo: Martins Fontes, 2004. 
OVÍDIO. Metamorfoses. São Paulo: Martin Claret, 2006.

PASCAL, Georges. O Pensamento de Kant. Petrópolis: Vozes, 1985.

PROBERT, Dulce María Granja Castro de. Estudio Preliminar. In: KANT, Immanuel. Crítica de la Razón Práctica, México, FCE, UAM, UNAM, 2005.

ROVIGHI, Sofia Vanni. História da Filosofia Moderna: da revolução científica a Hegel. São Paulo: Loyola, 1999.

TRUYOL Y SERRA, Antonio. Historia de la Filosofía del Derecho y del Estado. Madrid: Alianza, 1982. v. 2.

\section{ABREVIATURAS}

$B d \quad$ Band (Tomo, Volume)

$C R P \quad$ Crítica da razão pura

$C R P r$ Crítica da razão prática

$K r V \quad$ Kritik der reinen Vernunft (Crítica da Razão Pura)

Prolegomena Prolegomena zu einer jeden künftigen Metaphysik, die als Wissenschaft wird auftreten können (Prolegômenos a toda metafísica futura que queira apresentar-se como Ciência) 